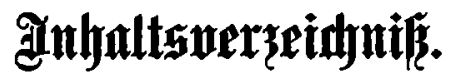

\section{Erfte 2lbtheilung.}

\section{fragen. (Mäiudlich $3 \mathfrak{n}$ erörtern.)}

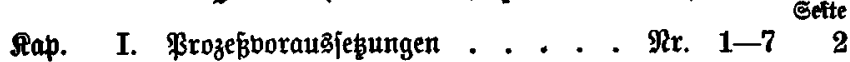

II. Bứtändigfeit . . . . . . . . " , 8-15 5

III. 3uftellungen. Labungen. $\mathfrak{B i e b e r =}$ einfegung . . . . . . . . " 16-23 9

IV. \$rozeß̧betheiligung . . . . . . " $24-3113$

V. Rlage, Einlaffung und mindituse Berfandlung . . . . . . . " 32-41 17

VI. Betweisberfahren . . . . . . "42-53 22

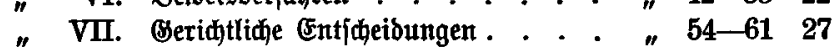

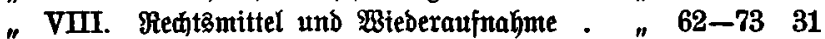

" IX. Bmangänollftredung . . . . . . " " 74-82 36

" X. Bejondere Ârten des Berfahrens. . " " 83-90 41

\section{$\widetilde{J}^{\text {weite }}$ Ubtheilung. \\ Anfgaben. (\$diriftlid) 3̈u bearbeiten.)}

I. Exftes $B$ ud. AIIgemetne Beft im= mutngen . . . . . . . . . $\Re x$ 91-109 44

II. Bweite $\mathbb{B} \mathfrak{B} \mathfrak{u}$ q. $B$ erfabreninerfter

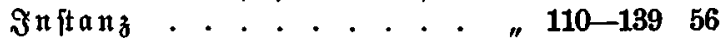

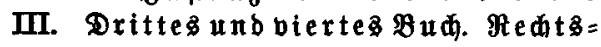
mittel. Wieberaufnahme bes Berfahrens. . . . . . . . 140-14973 


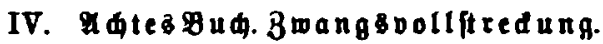

Sette

Arrejt. Einftweilige Ber=

fügung. . . . . . . . . . PR 150-16780

V. Zünftes, Sedites, Siebentes,

Neuntes unb Bebntes Bud.

urtundenprozeb. CGe=, $\mathcal{A}$ in $b=$

i由afts= und Entmünbtgungs =

iaqen. Wanbat $=$ und $\mathfrak{A} u f=$ gebotsoerfagren. Sqiebs= ridterlides Berfabren. . . "168-18090

Unbang I, II. 3nitanzenzug. - Enftem ber Cimilprojeforbunug. Angang III. Formulare. 